\title{
Simulating hydrological processes in a sub-basin of the Mekong using GBHM and RS data
}

\author{
WEI WANG ${ }^{1}$, HUI LU ${ }^{1,2}$, DAWEN YANG ${ }^{3}$, BIN GAO ${ }^{4}$, YANG JIAO ${ }^{3} \&$ \\ ZHIGUO PANG
}

1 Ministry of Education Key Laboratory for Earth System Modeling, and Center for Earth System Science, Tsinghua University, Beijing, 100084, China

2 Joint Center for Global Change Studies, Beijing, 100875, China.

luhui@tsinghua.edu.cn

3 Department of Hydraulic Engineering, Tsinghua University, Beijing, 100084, China

4 School of Water Resources and Environment, China University of Geosciences (Beijing), Beijing 100083, China

5 Remote Sensing Center, Institute of Water Resources and Hydropower Research, Beijing, 100044, China

\begin{abstract}
This paper presents simulations of daily hydrological process of the Mun River, the largest tributary of the Mekong, with a geomorphology-based hydrological model (GBHM) driven by two forcing sets: traditional station data and grid data derived from remote sensing and GLDAS products. Driven by the station data, the Mun-GBHM model is successfully calibrated against the discharge observed in 1991, but the model accuracy decreases with the increase of simulation time during the validation period of 1992-1999. Driven by the TRMM rainfall and other meteorological data from GLDAS, using the same parameters as above, the model performs reliably at both the monthly and daily scale. Moreover, when the model is calibrated with one year of gridded data, its performance can be further improved. Our results demonstrate that TRMM and GLDAS are able to drive the GBHM so providing reliable hydrologic predictions in such data-poor or ungauged basins.
\end{abstract}

Key words distributed hydrological model; TRMM; Mekong River; GLDAS

\section{INTRODUCTION}

As a combined result of climate changing, socio-economic development and population growth, water related problems, such as drought, extreme flooding and water pollution, are getting worse in the Mekong River basin (MRB) (Murray-Hudson et al., 2006; Evans et al., 2012). To mitigate these problems, a distributed hydrologic model (DHM), which can spatially simulate the whole hydrological cycle over MRB, is a powerful tool to undertake related research, such as evaluating the impacts of climate change on the hydrological cycle, flood forecasting and water resource management. But a DHM usually needs large amounts of input data to describe the spatial-temporal variation characteristics of the basin. Unfortunately, this requirement is difficult to satisfy, especially in underdeveloped areas such as MRB. For example, raingauges in MRB are distributed sparsely and unevenly, concentrating on cultivated regions along the main stream; few are in remote mountainous regions. Moreover, the gauge data or field survey data can only represent the state or properties in local scale and is different with those in a large scale (Boegh et al., 2004). As a result, the in situ measurements cannot be directly used in the DHM.

Aiming to overcome the problems listed above, the integration of remote sensing (RS) data and DHM has been a topic with large expectations during the last decades (Fortin et al., 2001). Nowadays, huge amounts of Earth observation data can be obtained easily on the internet, providing the possibility to simulate the hydrological cycle in the areas with scarce information (OnateValdivieso et al., 2014). For example, there are several popular satellite-based precipitation products, such as Tropical Rainfall Measuring Mission (TRMM), Climate Prediction Center MORPHing technique (CMORPH) and Precipitation Estimation from Remotely Sensed Information using Artificial Neural Networks (PERSIANN). These data source can provide high spatiotemporal resolution estimates of large-scale precipitation, which are very helpful for driving spatially distributed models at different spatial and time scales (Kim et al., 2014).

Taking the Mun River, the largest tributary of MRB, as an example case, this paper aims to check the feasibility of simulating hydrological process in a poorly gauged basin using a DHM driven by RS data. 


\section{DATA AND METHOD}

\section{Study area}

The Mun River (Fig. 1) carries approximately $26 \mathrm{~km}^{3}$ of water per year. The river begins in the Khao Yai National Park area of the Sankamphaeng Range, near Nakhon Ratchasima in the northeast (Isan) of Thailand. It flows east through the Khorat Plateau in southern Isan (Buriram, Surin and Sisaket provinces) for $750 \mathrm{~km}$, until it joins the Mekong at Khong Chiam in Ubon Ratchathani. The whole basin is fan shaped, and the northeast is higher and southwest lower.

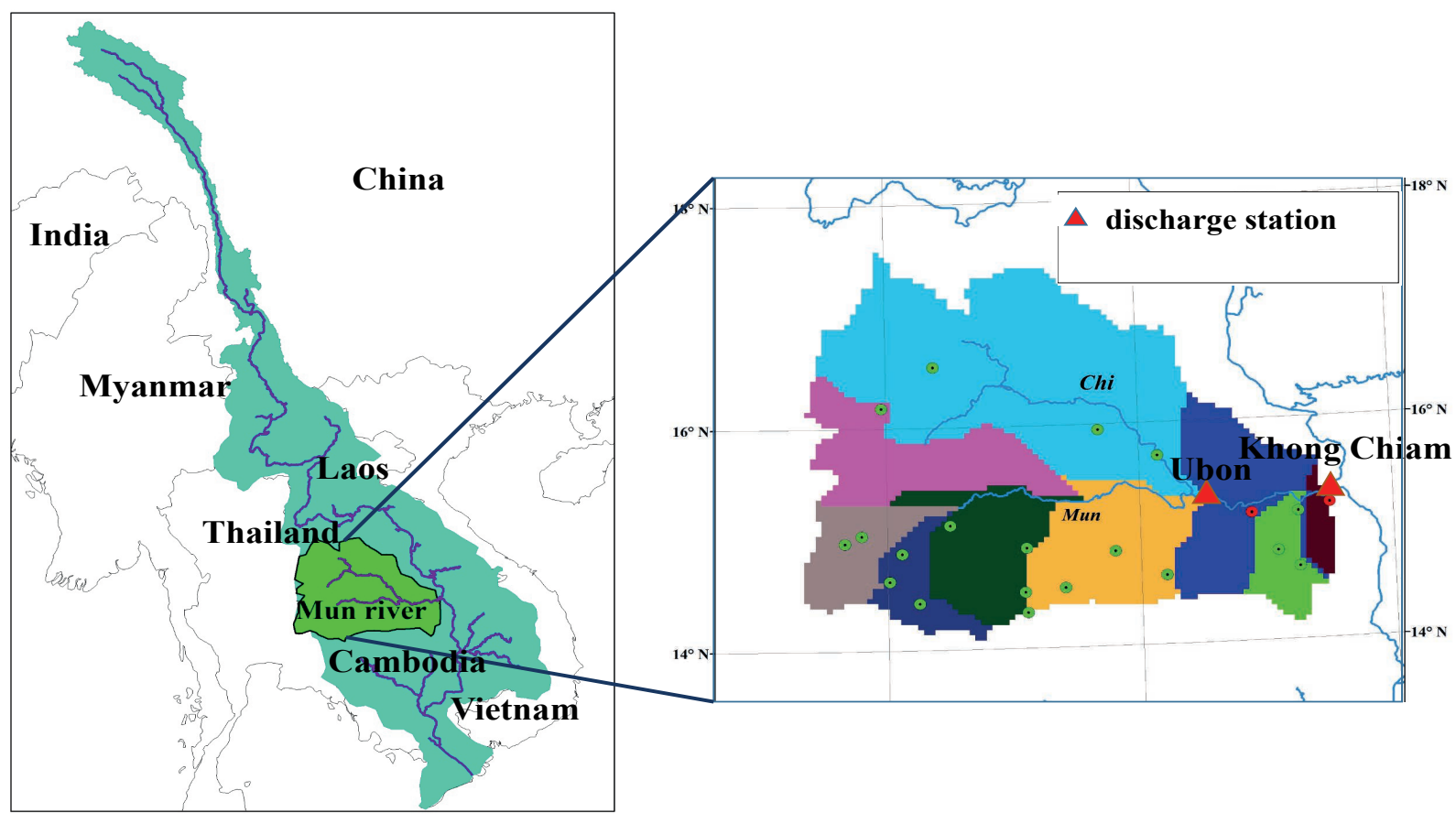

Fig. 1 Map of the Mun River basin.

\section{Model}

The DHM used in this study is the Geomorphology Based Hydrological Model (GBHM, Yang et al., 2002), which has four parts, the digital basin, hydrological simulation, data input and results output. A digital elevation model (DEM) is used to define the digital basin, which is subdivided into a number of fundamental units for hydrological simulation. The catchment parameters related to topography, land use and soil are then calculated for each simulation unit. Through establishing the digital basin, the study basin is divided into a discrete grid system, and the grid is represented by a number of geometrically symmetrical hillslopes.

In the hydrological simulation part of this model, a flow-interval hillslope scheme is applied to simplify the complex two-dimensional water kinematics to one-dimensional. A catchment is subdivided into a number of cascade-connected flow intervals following the flow distance from outlet to upper source by employing the area function and width function to lump the topography, so dividing the catchment into a series of flow interval-hillslopes (more details see Yang et al., 2002). A pair of hillslopes is located at each side of a stream segment. Impermeable bedrock is assumed to be parallel to the surface of each hillslope. The hillslopes in the flow interval are hydrologically similar without regard to the spatial variation of soil and land cover. For simplifying the stream network into a single main stream, all hillslopes are assumed to reach directly to the same main stream. The catchment runoff is the integrated hillslope responses through the river routing. 


\section{Data and materials}

We applied the method described above to the Mun River. Nine subcatchments were defined (as shown in Fig. 1). The $5 \times 5 \mathrm{~km}$ computational grid was extracted from $90-\mathrm{m}$ resolution DEM data provided by USGS (available from http://globalchange.nsdc.cn/page/index.vpage). The land use and land cover data were downloaded from the USGS 1-km Global Land Cover Characteristics Database. Soil type and soil depth data are from the Food and Agriculture Organization (FAO).

The in situ data were obtained from the historical observation data of the Mekong River Commission (MRC), including air temperature (mean, max and min), discharge, precipitation, relative humidity, sunshine duration and wind speed. We collected data from 19 rainfall stations and two meteorological stations in the Mun basin (Fig. 1). Discharge time series were obtained for Ubon station at the confluence of Chi, and Khong Chiam station at the outlet of the main stream.

TRMM3B42 daily precipitation data were used as remote sensing rainfall in this study. It was calibrated against ground raingauge observations at monthly scale to remove the bias of satellite retrievals. Evapotranspiration (ET) was estimated from the meteorological data provided by the Global Land Data Assimilation System (GLDAS). The GLDAS ingest satellite-based and groundbased observational data products, using advanced land surface modelling and data assimilation techniques, to generate optimal fields of land surface states and fluxes. The variables downloaded from GLDAS include near surface air temperature, near surface wind magnitude, net shortwave radiation and net longwave radiation.

\section{RESULTS AND DISCUSSION}

To measure the model performance for each test, two numerical measures, the ratio of the absolute error to the mean $(R E)$ and the modified Nash-Sutcliffe coefficient (Nash), were computed for the evaluation of the agreement between the simulation and observation of hydrographs using the following equations in which $\overline{o b s}$ and $\overline{s i m}$ represent the mean of observed and simulated discharge, and subscript $i$ refers to the time (day or month).

$$
\begin{aligned}
& R E=\frac{\overline{s l m}-\overline{o b s}}{\overline{o b s}} \times 100 \% \\
& N a s h=1-\frac{\sum_{i=1}^{T}\left(o b s_{i}-s i m_{i}\right)^{2}}{\sum_{i=1}^{T}\left(o b s_{i}-\overline{o b s}\right)^{2}}
\end{aligned}
$$

\section{Model calibration with station data}

The Mun-GBHM was calibrated against daily discharge data observed at Ubon and Khong Chiam in 1991. By adjusting bio-physical parameters, we attempted to make the model simulate the natural river precisely. The comparisons of observed and calibrated discharge at Ubon and Khong Chiam station are shown in Fig. 2(a), (b), (c) and (d), respectively.

From Fig. 2 we find that the Mun-GBHM performs quite well on the monthly scale, with a Nash of 0.87 at Ubon station and 0.89 at Khong Chiam station. Although at the daily scale the model performs a little bit worse than at monthly scale, it still has a Nash of 0.54 at Ubon and 0.79 at Khong Chiam. The ratio of the absolute error, $R E$ at Ubon station is $1 \%$, while $R E$ at Khong Chiam is $17 \%$. These results imply that the model performs well at both the daily and monthly scale, and the simulation at monthly scale is better than that at daily scale. From the viewpoint of different stations, simulation at Khong Chiam has a higher Nash score while that at Ubon has a smaller $R E$ value. This indicates that simulation at Khong Chiam station is better for the runoff process and at Ubon station is better for annual average runoff. Consequently, we can claim that this Mun-GBHM model simulates the discharge well during the calibration period, which means the parameters we calibrated in 1991 are efficient during the calibration period.

\section{Validations with station data}

The calibrated Mun-GBHM model was driven by gauge precipitation data and meteorological data, to test the model's stability. We ran the model for 1992 to 1999. The results are shown in Fig. 3. 

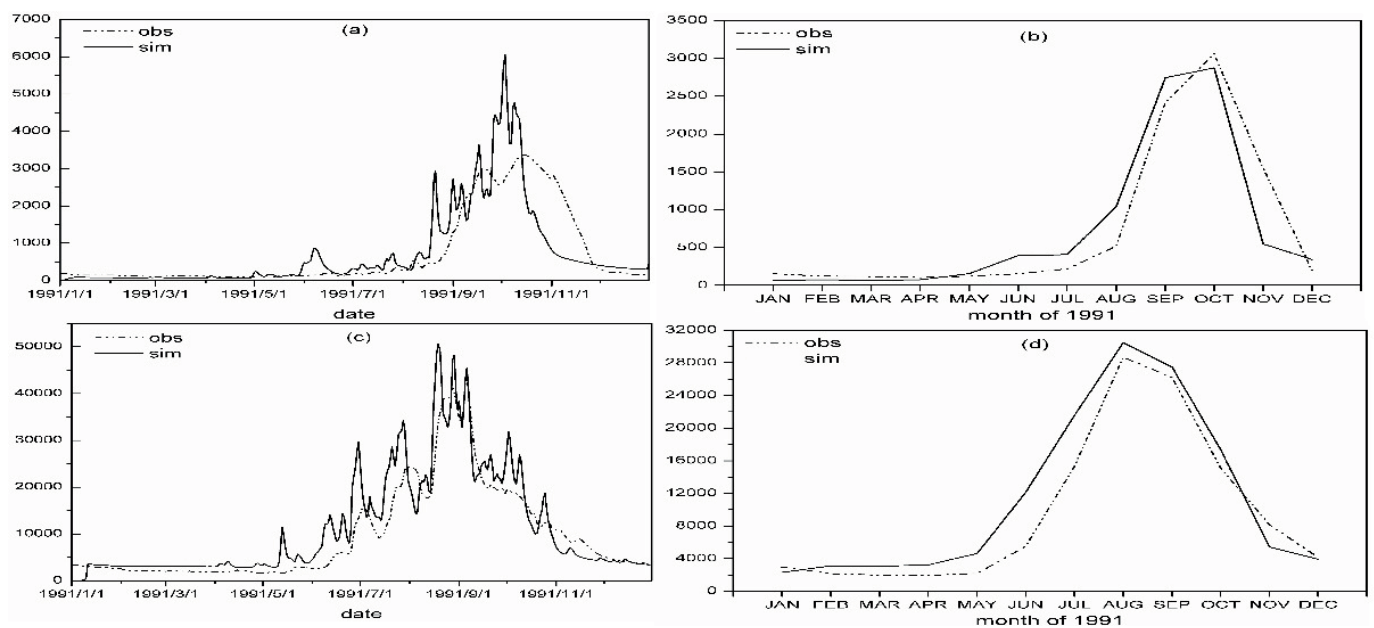

Fig. 2 Time series of daily and monthly discharge $\left(\mathrm{m}^{3} / \mathrm{s}\right)$ at the two stations during calibration period: daily series at Khong Chiam (a), monthly series at Khong Chiam (b), daily series at Ubon (c), daily series at Ubon (d).
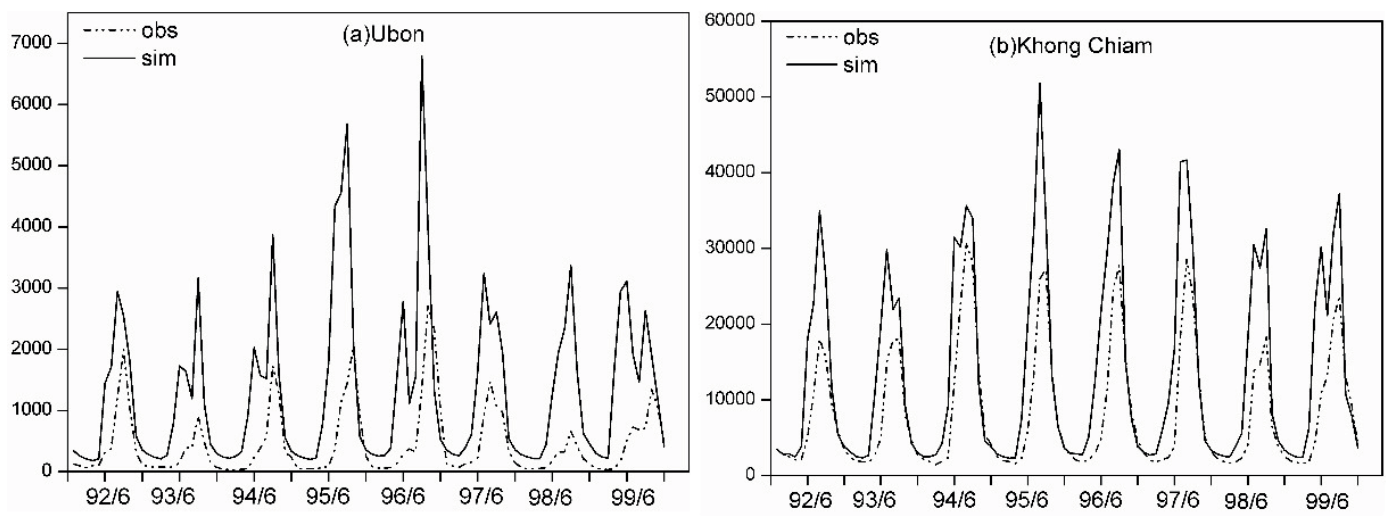

Fig. 3 Time series of monthly discharge driven by station data in 1992-1999/

At Ubon station, the model performance is not as good as that during the calibration period, with a Nash of -4.7 , which means the model is less trustworthy when driven by gauge data. Further, we can see that for 1992 the model's performance is not so bad, while during the later validation period (years 1998 and 1999), the simulated runoff is much larger than the observed one. MunGBHM performs similarly at Khong Chiam station, though the simulation result looks a little better than that of Ubon station, with a Nash of -0.1 . For both stations, the simulated discharge is higher than the gauge observation.

From these two figures we can conclude that the performance of Mun-GBHM in the validation period is not as good as that in calibration period when driven by gauge data. Since the GBHM have been successful applied in many basins with various climatic and geographic conditions, the physical basis of the GBHM is known to be reliable (Yang et al. 2002; Gao et al. 2008). It means, therefore, either the parameters or the forcing data (or both of these) are problematical. This may imply that the sparsely-distributed station data is not suitable for a spatially-distributed hydrological model in this region. Spatially-distributed forcing data, such as remote sensing products and re-analysis data, may be an alternative choice.

\section{Validation with TRMM and GLDAS data}

To check the reliability of the station data, the forcing data used in former section are replaced by the TRMM rainfall and ET estimated from GLDAS, while using the same parameters obtained from the calibration in 1991. Since the TRMM satellite was launched in November 1997, our simulation covers the period of 1998-1999, with a two year overlap of with former section. 
Figure 4 presents the comparison of observed discharge and discharge simulated when driven by TRMM and GLDAS. The Nash is 0.46 at monthly scale and 0.57 at daily scale for this two-year simulation, which is quite a good result compared to that obtained when driven by gauge data (see Fig. 3). In addition, Fig. 4 indicates an even better result at Khong Chiam station with a Nash of 0.44 at monthly scale and 0.67 at daily scale.
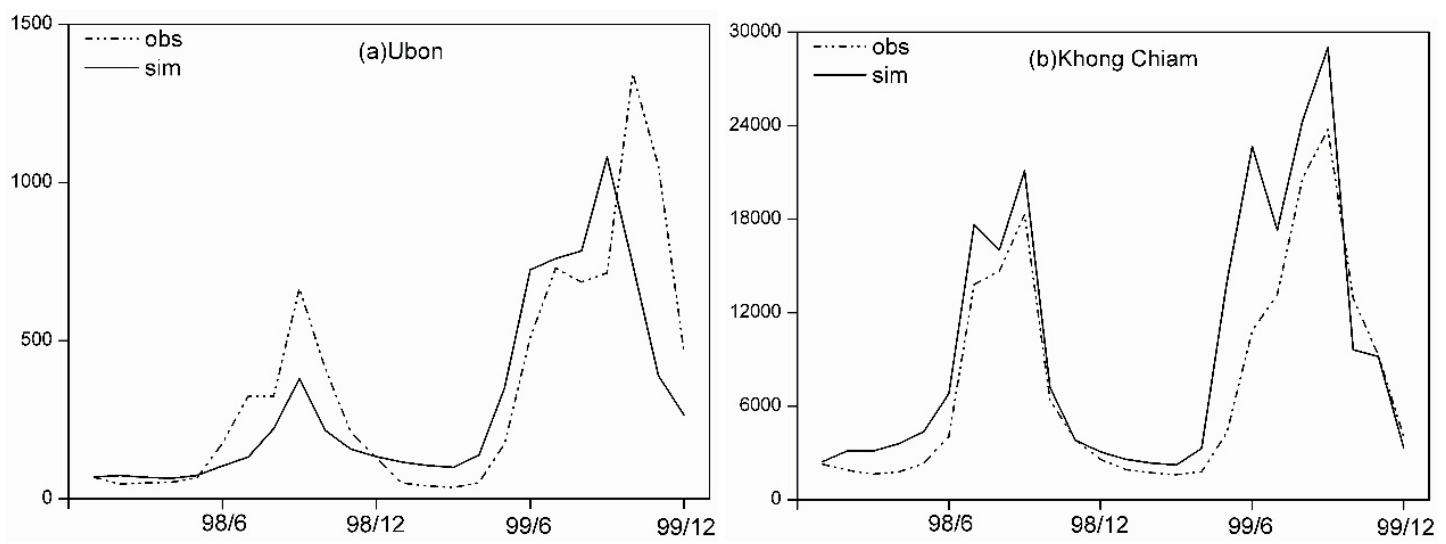

Fig. 4 Time series of monthly discharge driven by TRMM and GLDAS at Ubon (a) and Khong Chiam (b).

Table 1 The performance matrix of model driven by different data in 1998-1999.

\begin{tabular}{lcccccc}
\hline & \multicolumn{2}{c}{ Driven by station } & \multicolumn{2}{c}{ Driven by TRMM } & \multicolumn{2}{c}{ Driven by TRMM (calibrated) } \\
& Ubon & Khong Chiam & Ubon & Khong Chiam & Ubon & Khong Chiam \\
\hline Nash_daily & -4.00 & -0.27 & 0.46 & 0.44 & 0.52 & 0.73 \\
Nash_monthly & -4.70 & -0.17 & 0.57 & 0.67 & 0.60 & 0.89 \\
$R E$ & $257 \%$ & $159 \%$ & $-13 \%$ & $29 \%$ & $-7 \%$ & $5 \%$ \\
\hline
\end{tabular}

Table 1 summarizes the model performance during 1998-1999 when driven by different forcing data. It is clear that TRMM-driven simulation performs better than station-driven one, for both the Nash scores and $R E$.

Figure 5 shows the comparison of simulated runoff driven by gauge data and that by TRMM at the two stations during 1998 to 1999 . It is clear that, with the same model parameters, the daily discharge estimated by the TRMM-driven simulation is much closer to the observed one than the station-driven simulation. The station-driven simulation has obvious overestimation for whole period and for both stations. Such overestimation is inherited from the rainfall bias: the average daily rainfall in the basin of 1998 and 1999 is $15.13 \mathrm{~mm}$ and $16.34 \mathrm{~mm}$ for station-driven simulation, while $10.46 \mathrm{~mm}$ and $11.77 \mathrm{~mm}$ for TRMM-driven simulation. It is clear that the errors described in the former section are mainly caused by the low representativeness of the raingauge data.

\section{Calibration and validation with TRMM and GLDAS}

Finally, the model was calibrated with one year (1998) of TRMM rainfall and GLDAS data, and the model performance was further improved, with Nash around 0.7 at daily scale and 0.8 at monthly scale at Khong Chiam station (shown in Table 1). This results further prove that TRMM and GLDAS are able to drive the GBHM for making more reliable hydrologic predictions in this region compared to the gauge data. 

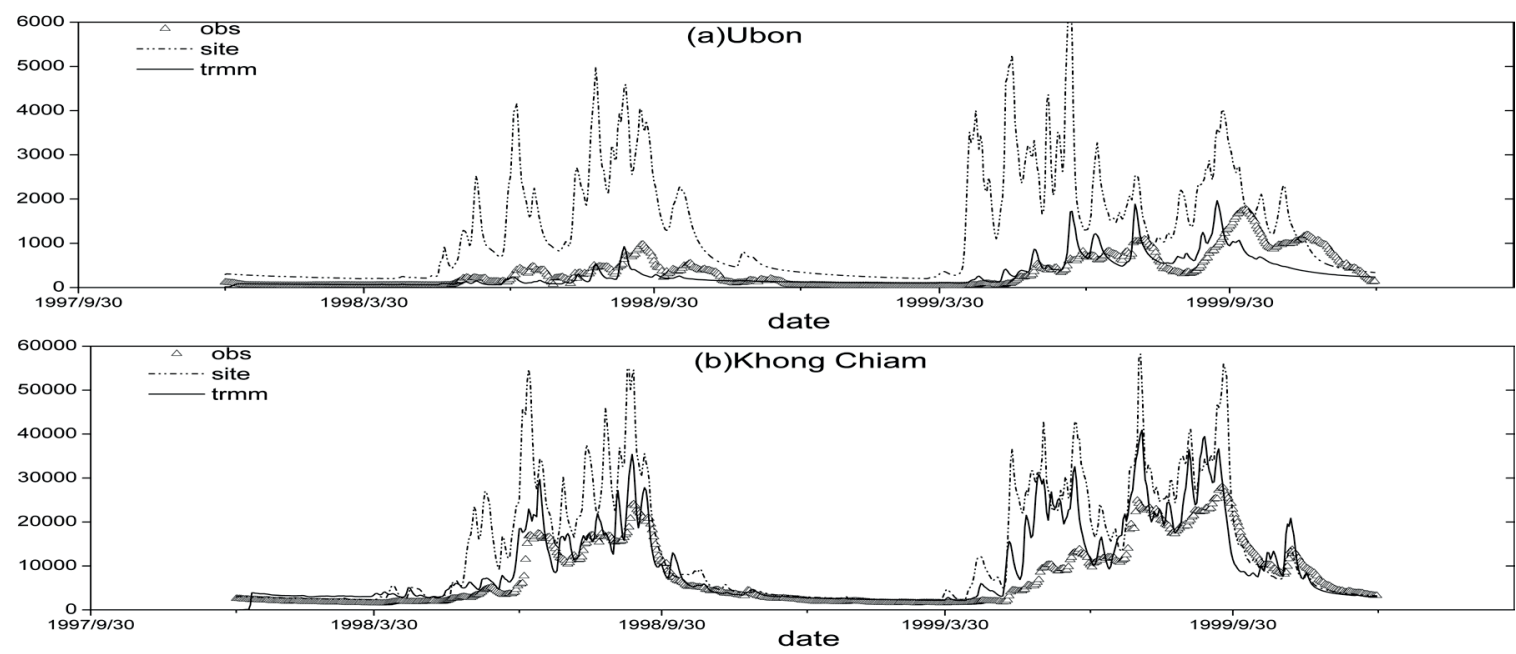

Fig. 5 Time series of daily discharge between at Ubon (a) and Khong Chiam (b) in 1998-1999.

\section{SUMMARY}

In this study, a distributed hydrological model was built for the Mun River by using publicly available free data to simulate the whole hydrology cycle of the basin. The model was calibrated by gauge data, and then driven by different input sources including station data and TRMM rainfall and GLADS data. Our study shows that sparsely-distributed gauge data may be less representative and problematic, which makes Mun-GBHM fail in validation, while TRMM and GLDAS are able to drive the GBHM for making reliable hydrologic predictions in this region. It means that the remote sensing data can be used to predict hydrological processes in such a poor gauged basin with this approach. Furthermore, this study also demonstrates that, for a spatially-distributed hydrological model, different input sources, especially the rainfall source, have a strong impact on the simulation effects. In a poor-data/ungauged basin, satellite-based data may be more suitable than the station data to drive a distributed hydrological model due to its advantages of being spatially-distributed, readily accessible and having long records of information.

Acknowledgements This work was jointly supported by the National " 863 " Program of China (2012AA12A309), the National Natural Science Foundation of China (51109111, 41371328 and 51190092), Tsinghua University Initiative Research Program (2011081132), and the Beijing Higher Education Young Elite Teacher Project (YETP0132). Most of satellite-based dataset was provided by International Scientific \& Technical Data Mirror Site, Computer Network Information Center, CAS. The site data were provided by the Mekong River Commission. The author would like to thank the High Performance Computing (HPC), Tsinghua University for the computational support.

\section{REFERENCES}

Boegh, E., et al. (2004) Incorporating remote sensing data in physically based distributed agro-hydrological modelling. Journal of Hydrology 287, 279-299.

Evans, A.E, et al. (2012) Water quality: assessment of the current situation in Asia. International Journal of Water Resources Development 28, 195-216.

Fortin, J, et al. 2001, Distributed watershed model compatible with remote sensing and GIS data. I: Description of model. Journal of Hydrologic Engineering 6, 91-99.

Gao, B, et al. (2008) Application of a distributed hydrological model for the Yarlung Zangbo River and analysis of the river runoff. Journal of China Hydrology, 28(3), 40-44.

Kim, S. and Brubaker, L. (2014) Comparison of gauge and MPE precipitation data for the Chesapeake Bay Watershed Model. Journal of Hydrologic Engineering 19, 1042-1047.

Murray-Hudson, M, et al. (2006) Scenarios of the impact of local and upstream changes in climate and water use on hydroecology in the Okavango Delta, Botswana. Journal of Hydrology 331, 73-84.

Onate-Valdivieso, F. and Sendra, J.B. (2014) Semidistributed hydrological model with scarce information: application to a large South American binational basin. Journal of Hydrologic Engineering 19, 1006-1014.

Yang, D., et al. (2002) A hillslope-based hydrological model using catchment area and width functions. Hydrological Sciences Journal 47, 49-65. 